\title{
Exploring Social Learning through Wiki in addition to Face to Face Interaction
}

\author{
Devaraj K \\ Department of Mechanical Engineering \\ BMS College of Engineering \\ Bangalore, India \\ devarajk.mech@bmsce.ac.in
}

\begin{abstract}
With the advent of social learning as a tool of instruction has shown a great promise in improving the sharing of information among the willful learners across the institutions. The current study is about the social learning activities in addition to the face-to-face class interaction. The experimental research was conducted with students enrolled in Basic Thermodynamics(BTD) course in the third semester of academic year 2014 and Turbomachines(TUM) in the fifth semester of academic year 2014. The students capability to adopt to the technology and use it as learning component in addition the class room teaching was tested. Students participation in peer review evaluation and learning from what their counterparts have commented on the solution were checked. Data were analyzed to show a significant increase in understanding the subject compared to the students who didn't participate in the Social learning. There were few minor drawbacks in implementing the social learning, but students showed lots of positive improvement in learning added to the classroom teaching.
\end{abstract}

Keywords- online collaboration, social learning, assignment, summarizing, peer review.

\author{
Devaraj K \\ Department of Mechanical Engineering \\ BMS College of Engineering \\ Bangalore, India \\ devarajk.mech@bmsce.ac.in
}

\section{Introduction}

Social Learning in the classroom with the aid of Technology will be a great boon in the field of Education. The students ability to learn things beyond classroom lectures will nurture them and show them the right path on how to be a successful lifelong learners. The penetration on high speed Internet and data available at the reasonable cost in the handheld devices such as Mobile phones and Tablet PC's, it becomes easier for the Teacher to reach the students in a much better and swifter manner compared to earlier days of conventional teaching.

Social Networking sites such as Facebook, Twitter, Whatsapp, Hike, have given a new dimension to the communication between the individuals. With the availability of Educational Wiki's at reasonable cost has made the sharing of information an easier task..

The natural inclination and ability to imitate things of social networking in the classroom through Wiki's is commendable improvement in imparting the Education. Learning through observing what others do had been documented by Professor Albert Bandura of Stanford University. Social learning looks at each individual in a different way with his interaction with the society, which will bring a change in his behaviour and its impact. Social learning observation can be in the form of attention to detail, retention to the information in his mind, reproduce what was learnt. During social learning, they may have difficulty in determining which information is relevant to them 
and how it will make a difference in the way they are learnt. If a correct technique is developed and imparted it will develop the student's ability to learn with the given instructions.

An example of social learning, can be related to Birds. The little bird observes his Mother trying to peck at the food, when it manages to peck through the top, it learns the taste of food and swallow it. So, the true role of social learning will be an efficient mechanism in transforming the education system. During the individual learning one student must invent a new behaviour during learning and can lead other during the social learning process. The situation, the learning environment and the behaviour of the students in contrast denotes how efficient the provided social learning system would be.

To facilitate better learning, wikis are used to engage the students in learning on priority basis in addition to class room lectures. As they research the content, they make connections to higher level of knowledge and share their experiences to the available content they are learning.

This study is identify how social learning through wiki would be effective in addition to the classroom lectures to address the following questions:

1. How different is the student's understanding capability of the content available in wiki.

2. Is there a difference in satisfaction of students learning via wiki.

3. How social learning would add value to the existing classroom learning.

\section{Literature review}

Many researchers are conducting studies to promote the use of wiki's in education. Mak \& Coniam[1] used wiki for enhance the writing skills among the secondary school students in Hong Kong. In a six-week project, they explored whether students engaged in collaborative writing using wikis will be able to produce a better than their normal weekly writing assignments. Their data was analyzed from the writing involving a sub-group of four students where the students are allowed to produce, revise and edit the material for preparation of brochure. Franco[2] used wiki for peer review for a group of students and found a significant improvement in language skill post-peer review assessment compared to pre-peer review assessment. The aim of the analysis was to determine whether the students writing skill will see an improvement or not. The results suggested that wikis provide learners a better environment in developing their writing skills. Similarly Lee[3] reported a case study involving 35 students using wiki for collaborative writing. His results showed that creating wiki's had a significant positive impact on students writing skills over a period of 14 weeks. It also showed that good moderation of wiki's by providing hints and tips during their creation and revision process.

From the literature review, I tried answers to the following questions:

1. Do learners develop their learning skills through wikis in groups.

2. How the learner of one particular group evaluate the work carried out by the leaner in other group

\section{Methodology}

The study was examined at the social learning, process approach to summary writing and peer review participation with online questionnaire conducted.

\subsection{Participants}

The participants involved in the study are the 169 students of third semester and 52 students of fifth semester students from undergraduate Mechanical Engineering of BMS College of Engineering, Bangalore, India. The students are interested in learning things outside the classroom through active participation, like surfing the internet and active members on social networking sites such as Facebook or Twitter. Few students are found to have better command over connecting through online, while others need to improve this skill in terms of accuracy

\subsection{Instruments}

The impact of students learning through alternate assessment was evaluated by four instruments including wiki instructions and discussion, summary writing tests, assignment submission and peer review participation.

First, to learn how well the instruction through wikis are accepted and improve their capability of learning.

Second, the summary writing skill of two journal papers or conference papers or articles related their subject. 
Third, to submit an assignment consisting of questions related their subject of study within their syllabus and beyond it.

Fourth, Students participation in posting their experience of working through the assignments with their peers on their wiki page.

\subsection{Procedure}

In the first stage, the teacher shares the information through short videos, word or pdf documents, reference links through wiki pertaining to their subject of study within their syllabus and beyond. Students have to participate actively in learning from the wiki through social networking platform and discuss their learning's among their students moderated by the teacher.

In the second stage, the students are divided into group consisting of 5 students using the wiki tool and assigned as private group. The students can interact within the group, like sharing the documents, comments, discussion privately. Each group of Students have to refer to two technical journal or conference or articles related to their subject of study. The students are taught how to summarize the paper in the classroom and find out the topic of their choice. The third semester students should refer to papers in Thermodynamics while the fifth semester students should refer to papers in Turbomachines or Fluid Machinery. Each group of students are required to read these articles and write a summary for each paper in a paragraph of less than 750 words, with the time allowed for these activity is 1 week and upload the same to the wiki. The students should prepare a PowerPoint presentation consisting of 8 to 10 slides and present the same to other students and are evaluated by the teacher and other students in the classroom. After every group has finished the task, the assigned groups are made public so other students can participate and express their comments in their respective group wiki.

In the third stage, the students of the particular group have to submit the group assignment consisting of questions from their respective subject and their learning's from the wiki and upload the solutions to their respective group wiki.

In the fourth stage, the group assignments are made public so all the students have access to the solutions, and do a peer review of the solutions submitted by other groups. Discuss and comment on what they learnt from the solutions submitted by other group members.

\section{CASE STUDY:}

\section{Length:14 Weeks (One Semester)}

\section{Level: 2nd Year Basic Thermodynamics course}

No. of Students: 49

Aim: To demonstrate the relevance of social learning and Peer evaluation. Encourage the students to use wiki as source of knowledge other than class room lectures.

Key skills: Group work, presentational skills, time management, peer assessment

\section{Assessment:Question sheet and group presentation}

Task-1: All the students are formed a group named "BTD-Mech" with faculty as moderator on Wiki. Faculty and students are allowed to share their learning's into Wiki in the form of Documents, Videos, Web links etc., Students can learn from these learning's whenever they desire from the Wiki outside the classroom. Students can like the learning, comment on the learning by posting questions which can be answered by other students of the group or by the Moderator.

Task-2: Students are assigned to groups of 5 for the study. Each group is provided with two refereed Journal/Article/Conference papers of present research. The students have to go through the paper in one week time and have to summarize each paper into one paragraph of not exceeding 750 words in their own words and share it on wiki. The students have to share their knowledge from others by making a presentation in the class and engage themselves in the discussion with other group members. A set of questions answered by the group has to be peer reviewed by other group members through comments on the wiki.

\section{Results}

The students ability to learn is based on the results to the following questions:

1. To what extent students are able to improve their 
summary writing and presentation skills other than their regular classroom writing and examination.?

Students showed a significant improvement in their writing abilities pre and post submission, which shows their ability to understand the potential of research activities in their field of subject.

2. What are their attitudes towards the learning method?

Out of 169 students of third semester students 76 students are actively involved in social learning activity showing a $45 \%$ participation. While 43 students out of 52 students of fifth semester students participated in social learning showing a $82.7 \%$ participation. In terms of interactions through wiki there were more than 950 interactions from third semester students while around 380 interactions from the fifth semester students. Interactions include comments, like, learn, rate, share etc.,

3. What did the students get in terms of social learning through wiki?

Students were asked to express their feelings through a survey using Google form, it was found that 55 out of 169 from third semester and 38 out of 53 from fifth semester agreed that wiki is a new learning experience, compared to their conventional way of learning.

4. Is there a difference in students peer review evaluation and those using conventional evaluation from the teacher?

61 students out of 169 students from third semester students participated in peer evaluation, while 40 out of 53 students participated in the peer evaluation from fifth semester. Majority of the student learners reaction was optimistic to peer-correction, with an appreciation to the fact that through wiki they are in a position to look at what other students have written. It has created an awareness of evaluation process among the student participants.

5. Whether wiki has enabled them to develop cooperative skill with others?

48 students out of 169 from the third semester and 47 out of 52 students from fifth semester actively participated in group assignment and found that cooperation among the group members have led to better preparation and presenting the technical papers during the classroom presentation.

6. Whether social learning, has created a platform for the students in helping each other to learn.

50 out of 169 students from third semester and 5 out of 52 students from fifth semester were found wiki's being very helpful to them. All the active members of the third and fifth semester who are actively involved are found helping each other in completing their assignment and peer discussion.

\section{Discussion and Conclusion.}

The findings clearly indicate that wikis are an effective social learning's tools which can contribute substantially to improve the learning ability of the students. A systematic approach to the usage of wiki in addition to the conventional teaching will add a new dimension to the teacher student interaction within and outside the classroom. The motivation to learning has increased significantly. The students while evaluating their peers has experienced a higher level of responsibility and autonomy, while becoming less dependent on the teacher. In an online environment wikis have become a significant favorable tool to the students, providing more opportunities to keep them engaged during the learning process. The most gratifying achievement during the process that it was more of cooperation environment rather than a competitive environment to evaluate themselves. With the rapid increase in Web-2 tools in the field of education, the teacher's role will be in the direction more of a facilitator rather than just delivering the lecture in the conventional classroom. Also Web-2 tools like wikis will provide an opportunity to unlock the potential of the students and invoke them the benefits of social learning.

\section{Acknowledgment}

I would like to thank our Principal and Head of the Department of Mechanical Engineering of BMS College of College, Bangalore for their constant motivation to align our teaching methodology in line with Out-come Based Education standards.

\section{References}

[1] Mak, B., \& Coniam, .D, "Using wikis to enhance and develop writing skills among secondary school students in Hong Kong". System, 36 (3), pp 
437-455, 2008.

[2]Franco, C., "Using wiki-based peer-correction to develop writing skills of Brazilian EFL learners', Novitas-ROYAL, 2008, Vol.2 (1), pp 49-59, 2008.

[3]Lee, Lina, "Exploring Wiki-Mediated Collaborative Writing-A case study in an Elementary Spanish Course", CALICO Journal, Vol.27(2), pp 260-276, 2010.

[4]Bandura, Albert., "Social Learning Theory", Prentice-Hall, 1977
[5]Wichadee, Saovapa., "Using Wikis To Develop Summary Writing Abilities Of Students In An EFL Class", Journal of Collage Teaching \& Learning, Vol. 7(12), 2010.

[6]Wu, J. H., Tennyson, R. D., \& Hsia, T. L., "A study of student satisfaction in a blended e-learning system environment", Computers \& Education, 55(1), pp 155-164, 2010. 